\title{
Changing of Polyethylene Film Structure during Long-Term Aging
}

\author{
${ }^{I}$ Lviv Trade and Economic University, Lviv, Ukraine, e-mail: nina.domantzevich@gmail.com, \\ ${ }^{2}$ National University "Lviv Polytechnic”, Lviv, Ukraine, e-mail: bogdan.yatsyshyn7@gmail.com,
}

\begin{abstract}
The study of surface structure of polyethylene films after their manufacture and later 7 years of closed storage were carried out. Electron-microscopic studies have revealed the features of the structure formation and aging processes, depending on the amount of organic and organic-mineral fillers, as well as the characteristic features of the destruction of the polymer material matrix.
\end{abstract}

Key words: polymers, polyethylene films, filler, structure, aging, closed storage.

Received 12.02.2020; accepted for publication 15.03.2020.

\section{Introduction}

Polymer films based on thermoplastics as a technical material in the manufacture of membranes for separation of gas and liquid environments, technical parts of sensors and separators are increasingly used. Their use requires the correction of definite physical characteristics, which is carried out by various additives and fillers of the polymer matrix. However, the improvement of some characteristics may be accompanied by a decrease in the other physico-mechanical and chemical appearance of the material, which necessitates further research.

The purpose of the study was to determine the changes in the structure of polyethelene films modified with organic and inorganic fillers during long-term aging under closed storage conditions.

\section{Experimental part}

The thin-film polymer materials with filler were obtained on an industrial plastic extrusion machine. The starting materials for the manufacture were granules of LDPE 15803-020, and organic (up to 9 wt.\% - casein) and mixed organic-mineral (up to $30 \mathrm{wt} \%$ ), known under the commercial names Credolen and Vatpol 210, as fillers also used. Various technological applications up to $4 \mathrm{wt}$. \% were injected for providing the technical parameters of composition. The thickness of the polymer films ranged from $45 \mu \mathrm{m}$ to $50 \mu \mathrm{m}$.

Electron microscopic studies were performed on an EVO 40XVP electron microscope. The samples were subjected to pre-ion etching on a device VUP-4 and cut over with gold to ensure charge drainage for contrast.

\section{Research results}

Newly formed polyethylene films were characterized by a fairly flat surface with a small defect. The initial crystallization, which should cover rather large volumes of the polyethylene matrix, was revealed as small crystalline formations $\left(\ell \approx 0.2 \cdot 10^{-6} \mathrm{~m}\right)$, scattered uniformly on the surface (Fig. 1).

The total volume of the crystalline phase, judging by the flow of crystallite nucleation processes in initial unmodified films, was estimated at $30 \%$, which is quite plausible, given to acount the technological additives that lead to the preservation of the amorphous state (lubricants, slip agents, etc.). The films of unmodified polyethylene film materials were characterized by a minimal quantity of structural imperfections with maximum linear dimensions of $\ell \leq 0.4 \cdot 10^{-6} \mathrm{~m}$.

The filler additives, depending on the type and amount of material used, change the surface structure of freshly formed films in different form. The additives of organic filler (casein) smooth the surface, reducing the quantity of crystallites and small crystalline formations, although the total volume of the crystalline phase 
decreases slightly, since favorable conditions for their formation are created (Fig. 2).

The casein modified films had a structure that was significantly different from the structure of the unmodified samples. Output sizes of crystals of polyethylene reached $\ell_{\mathrm{cr}} \approx 6.5-9 \cdot 10^{-6} \mathrm{~m}$. Remains of discrete technological applications that did not interact with the main matrix or form insoluble compounds had linear dimensions $\ell \approx 1.5 \cdot 10^{-6} \mathrm{~m}$. That is the violate of coating integrity and such primary defects of the surface as recesses, caverns and cavity with $\varnothing_{\text {cav. }}=0.4$ $0.9 \cdot 10^{-6} \mathrm{~m}$ were formed. Micrographs of initial caseinmodified polyethylene films did not reveal such defects as cracks and through pores, although some conglomerate accumulations could be considered as the initial origin of the cracks.

Additives of mixed filler, even with a small amount of weight (up to 10 wt.\%), significantly changed the structure of the surface. The surface of the film has a wavy appearance with a large number of splashes of the mineral component of the filler, the linear size of which varies from $\ell_{\text {fil. }}=0.4 \cdot 10^{-6} \mathrm{~m}$ to $\ell_{\text {fil. }}=2 \cdot 10^{-6} \mathrm{~m}$, when the content of the aditives are more than $15 \mathrm{wt} . \%$. It should be noted that the aditives material was evenly distributed over the film surface and did not create clots, conglomerates and other large formations (Fig. 3).

Additives of various types of organic-mineral fillers in the amount of more than $20 \mathrm{wt}$. \% significantly change the surface morphology of the film polymer material - a great deal of mineral material is displaced outward and covers the surface of the surface in the form of asymmetrical inclusions, the size of which could reach $\ell_{\text {fil. }}=8 \cdot 10^{-6} \mathrm{~m}$ (Fig. 4).

The addition of such a large amount of filler led to changes in the surface structure of the composite, and to appearance of surface formations in the polymer matrix. A large number of matrix defects are precisely connected with the incompatibility of the physicochemical characteristics of the composite materials. Technological additives in the form of lubricants and plasticizers are not able to compensate for the discrepancy of structural characteristics of materials that develop into the appearance of caverns, cracks and pores already in the initial stages of the life cycle of a polymer product.

An increase in the addition of the same Vatpol-type filler (up to $23 \mathrm{wt} . \%$ ) led to an increase in sizes of intramatrix crystalline formations (up to $\ell_{\text {cr. }} \approx 4 \cdot 10^{-6} \mathrm{~m}$ ) and to slight decrease in pore diameter (up to $\varnothing_{\text {por }}=0.6 \cdot 10^{-6} \mathrm{~m}$ ), although the level of general defect in the surface

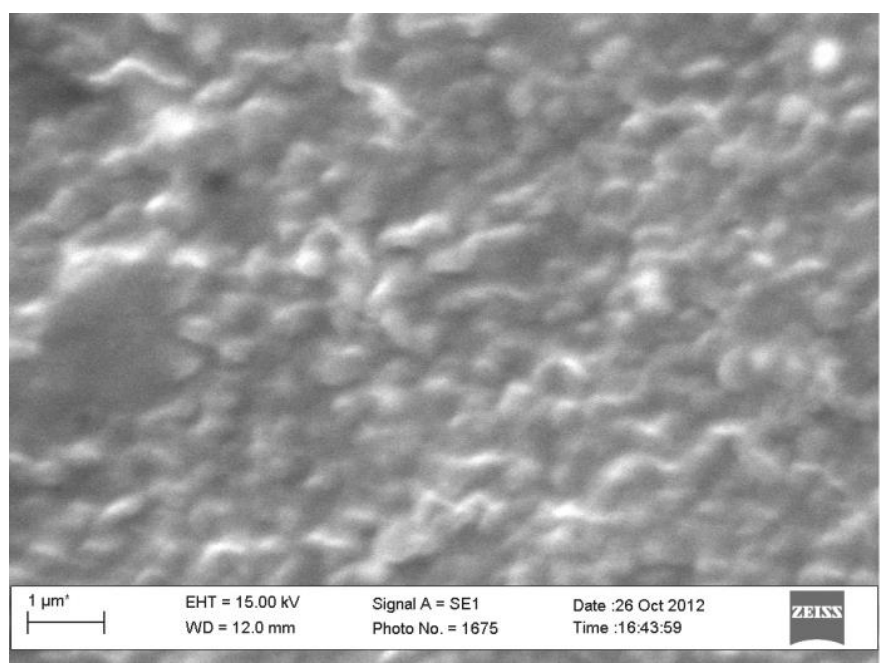

Fig. 1. The surface structure of the initial unmodified polyethylene film (X 10000$)$.

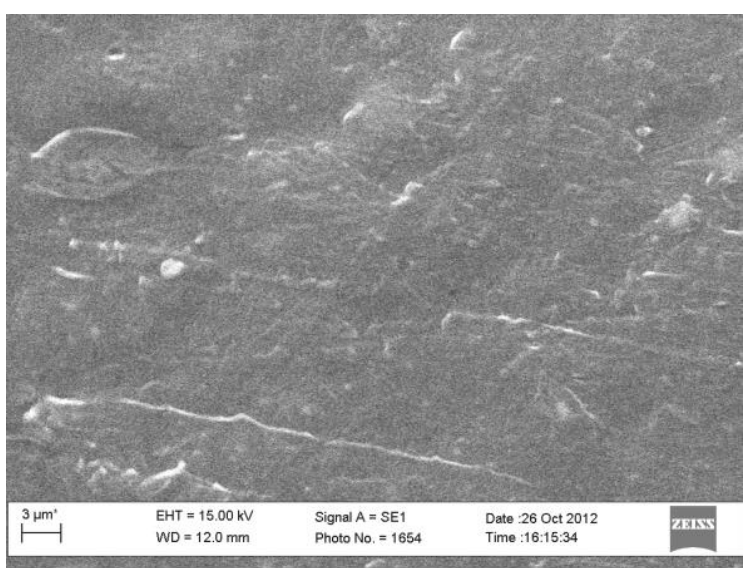

a

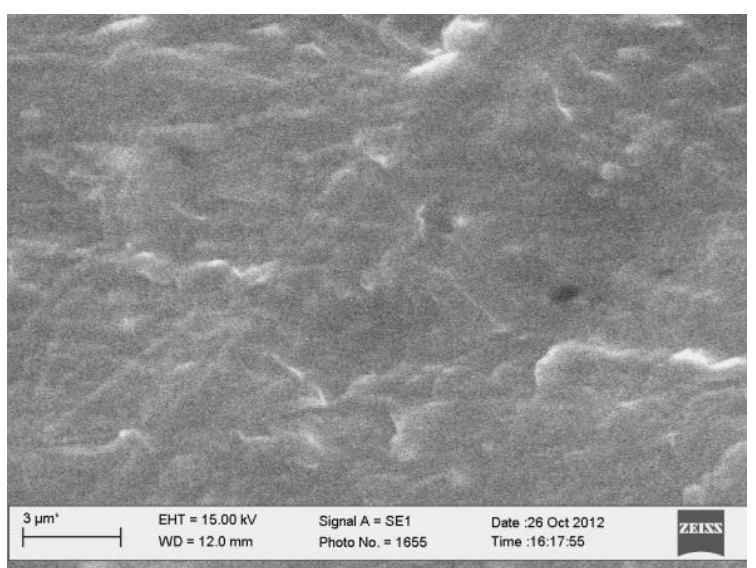

b

Fig. 2. The surface structure of polyethylene film with casein additives (8.6 wt.\%): a - X 2 000; b - X 5000 . 
structure of the sample remained (Fig. 5).

The Credolen filler was bigger - some of its particles reached the size of $\ell_{\text {fil. }} \approx 10 \cdot 10^{-6} \mathrm{~m}$.. The structural defects of the matrix where pores $\varnothing_{\text {por }}=$ $2 \cdot 10^{-6} \mathrm{M} \mathrm{m}$ were observed increased in size, respectively (Fig. 6).

Increasing of the volume of mixed filler to $28 \mathrm{wt}$. \% led to the formation of separate conglomerate formations

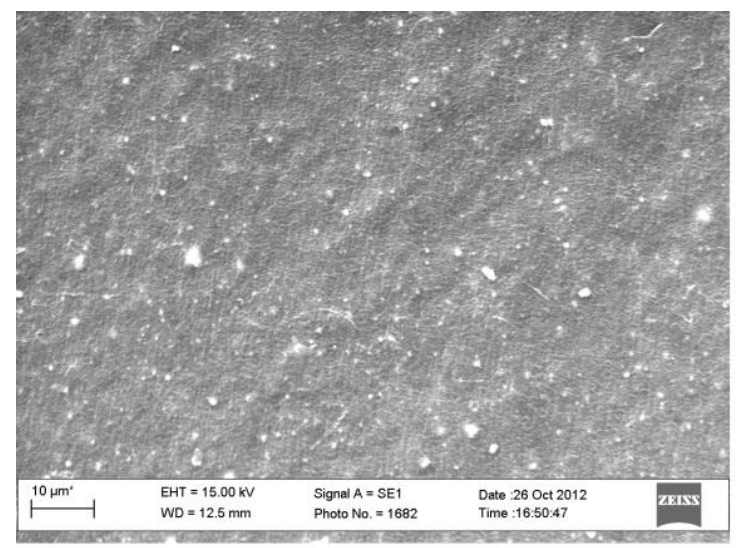

a from particle with the size up to $\ell_{\text {fil. }} \approx 4 \cdot 10^{-6} \mathrm{~m}$, which coagulated, and, at same time, the increasing of total surface defect observed (Fig. 7).

Aging of polymer films with fillers under closed storage conditions changes the structure of the surface and, depending on the type and quantity of filler, may alter the crystallinity of the sample or increase the structural imperfections of the surface. Thus, the aging of

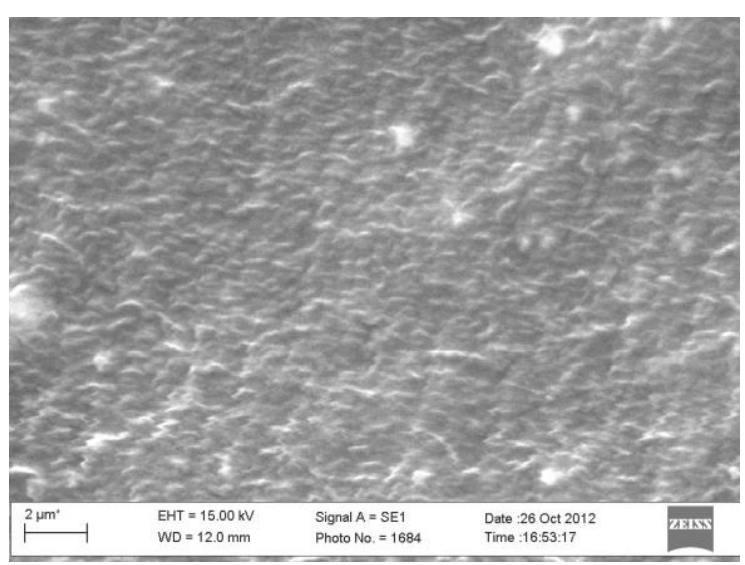

b

Fig. 3. Morphology of the film surface with additives of mixed filler type "Credolen" (16.1 wt.\%): a - X 1000; b - X 5000 .

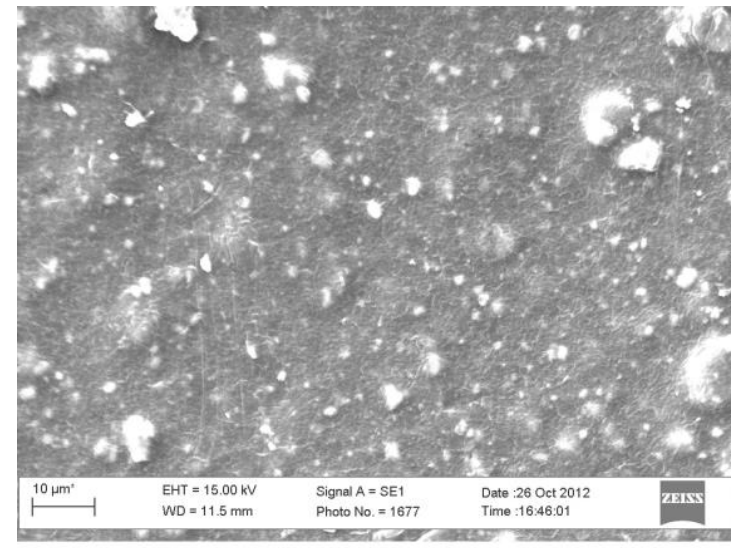

a

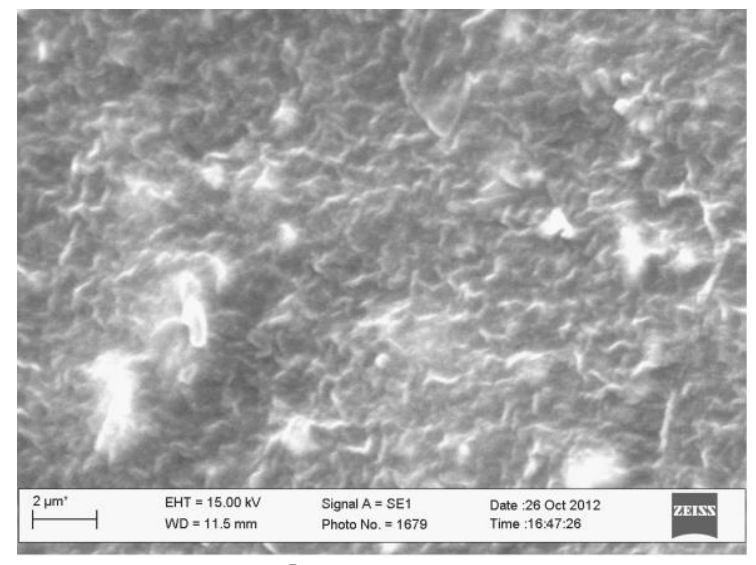

b

Fig. 4. The surface structure of polyethylene film with mixed Vatpol filler (21wt.\%): a - X1000; b - X5000.

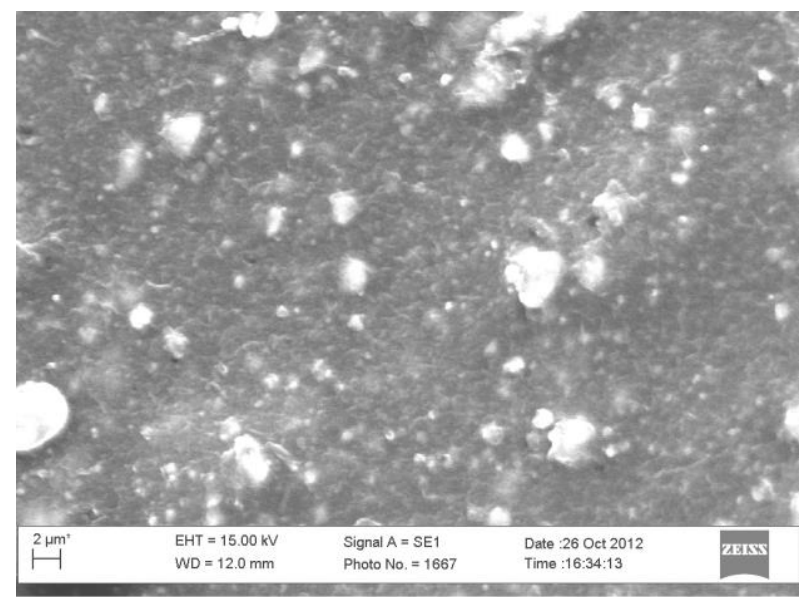

Fig. 5. The surface structure of polyethylene film with mixed Vatpol filler (22.6 wt.\%): X 2000. 


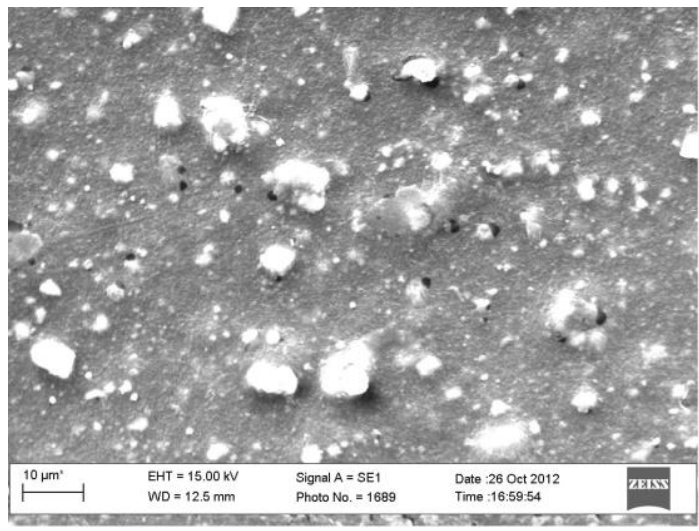

$\mathbf{a}$

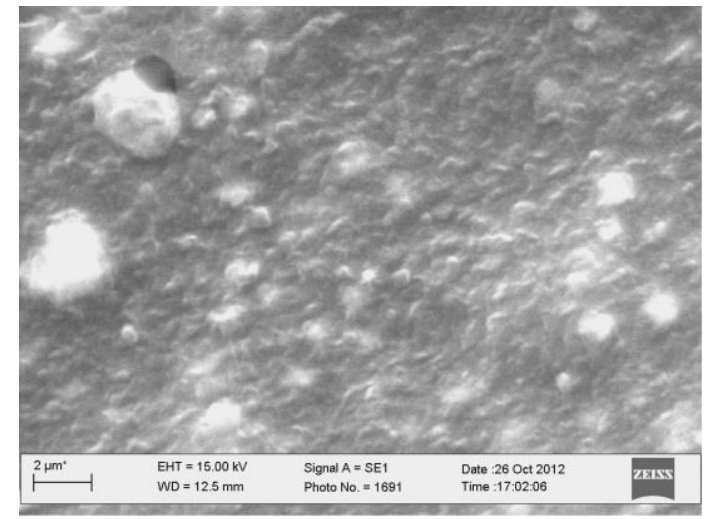

b

Fig. 6. Electron micrograph of the surface of polyethylene film with the addition of a mixed organic-mineral filler Credolen (23.2 wt.\%): a - X 1000; b - X 5000.

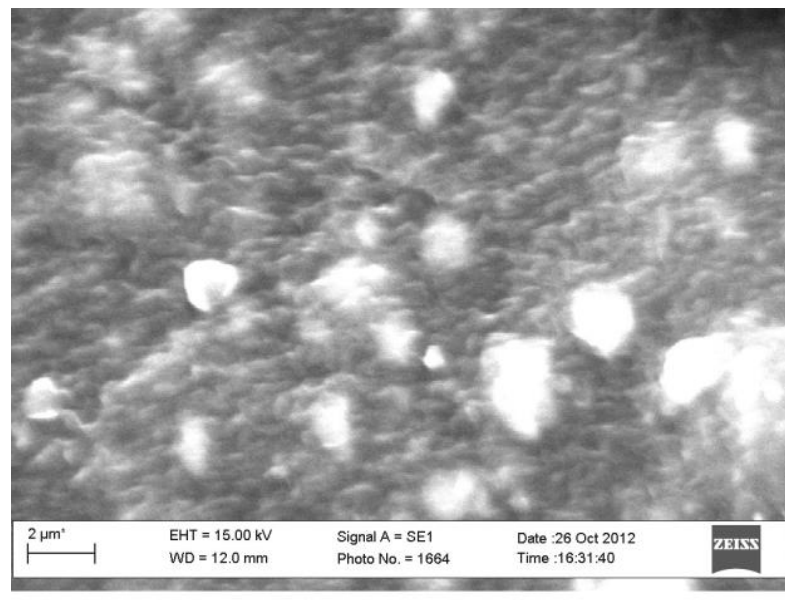

Fig. 7. Morphology of the surface of a polyethelene film, manufacted with the addition of Vatpol mixed filler (up to 28 wt.\%). X 5000.

polymer films with casein-type filler to a greater extent influenced the passage of intra-matrix processes. Moreover, the flow of single crystallization in the initial formed polyethylene film was supplanted by multiple processes of crystallite formation, which during growth "layered" one on other (Fig. 8).

This structure in the form of a "track" of crystals is characteristic of accelerated studies or the aging of polyethylene materials that contain accelerators of crystallization processes (eg, amines). The length of such crystalline layers could be up to $\ell \approx 2-16 \cdot 10^{-5} \mathrm{~m}$. Such formations in the future will certainly projected as sources of defect with penetrating pores and cracks in the film. Large cracks $\left(\ell_{\text {crack. }} \approx 1-1.2 \cdot 10^{-5} \mathrm{~m}\right)$ and pores $\left(\varnothing_{\text {por }}=1.2-1.5 \cdot 10^{-6} \mathrm{~m}\right)$ were found in some places of surface. Aging of polyethylene films with casein, despite the significant change in their phase composition, did not significantly impair the integrity of the coating, although some large defects could have a serious influence on the physical and chemical characteristics of the material.

It should be noted that the storage of film material up to 7-8 years in the form of a multiple convolution or roll, has the same effect on the overall development of defect formation processes and leads to one result - an increase in the size of defects with corresponding changes in

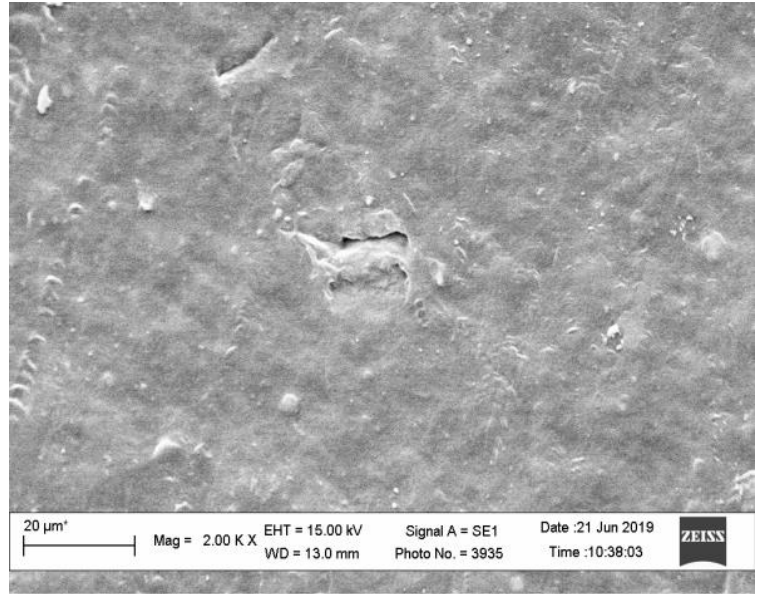

Fig. 8. Electron micrograph of the surface of the plastic film with casein additives (8.6 wt.\%) For 7 years of storage. (X 2000).

physical and chemical characteristics.

Addition of 16.1 wt.\% Credolen filler changed the nature of the structure during aging. Intra-matrix crystallization with the formation of polyethylene crystallites was reduced compared to films with casein additives. Single formation in the crystallite form of "tracks" $\left(\ell_{\text {track }} \approx 6 \cdot 10^{-5} \mathrm{~m}\right)$ were placed along technological defects of production (scratches from the extruder head, etc.) (Fig. 9a). The crystallites could form on the surface at the places of exit of the mineral component of the filler, as well as the defect of the coating on the boundary "crystalline-amorphous phase" increased and cracks appeared $\ell_{\text {crack. }} \approx 1.5 \cdot 10^{-6} \mathrm{~m}$ (Fig. $9 b)$.

The pores were small $\left(\varnothing_{\text {por. }}=0.6 \cdot 10^{-6} \mathrm{~m}\right)$, although the some separate specimens had a size up to $\varnothing_{\text {por. }}=$ $3 \cdot 10^{-6} \mathrm{~m}$. The mineral additives were placed in the matrix evenly, did not create heaps.

The increase of the Vatpol organic-mineral filler in the composition of the polyethelene film up to 21 24 wt.\% significantly changed the appearance of the surface, which took the form of a densely dusted by additive (Fig. 10, a, b). The linear dimensions of the filler did not go beyond $\ell_{\text {fil. }} \leq 8 \cdot 10^{-6} \mathrm{~m}$. But, the increased of quantity of additive contributed to the increase of the 


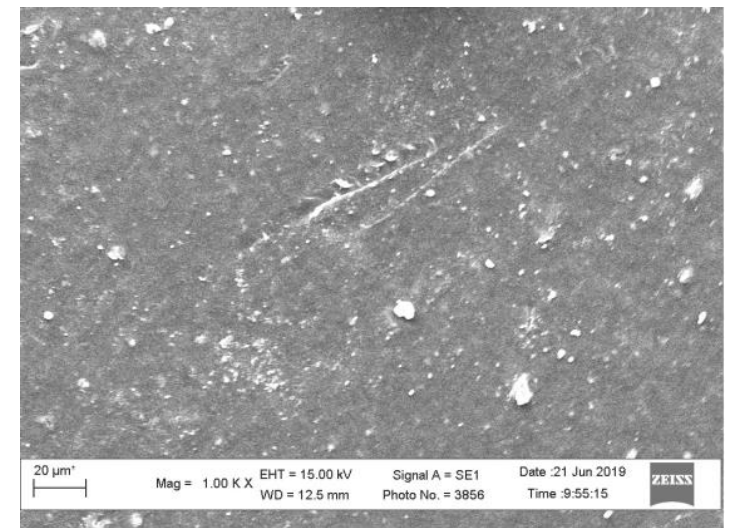

a

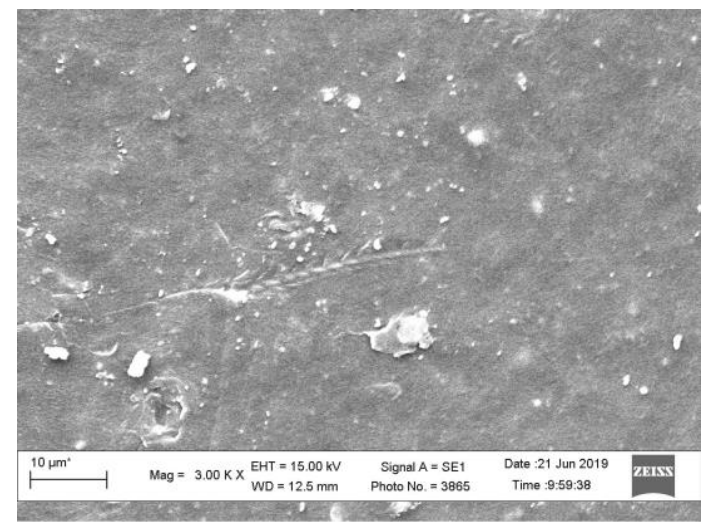

b

Fig. 9. Peculiarity of the surface structure of the film, modified by Credolen filler (16.1 wt.\%) for 7 years of storage: a - X 1000; b - X 3000.

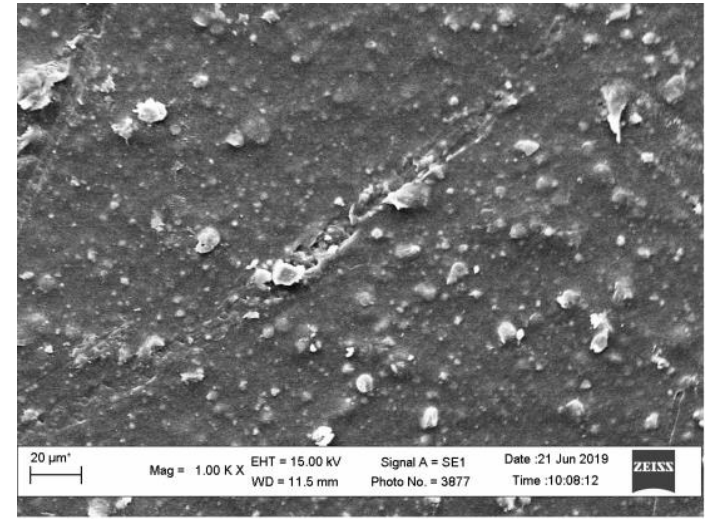

a

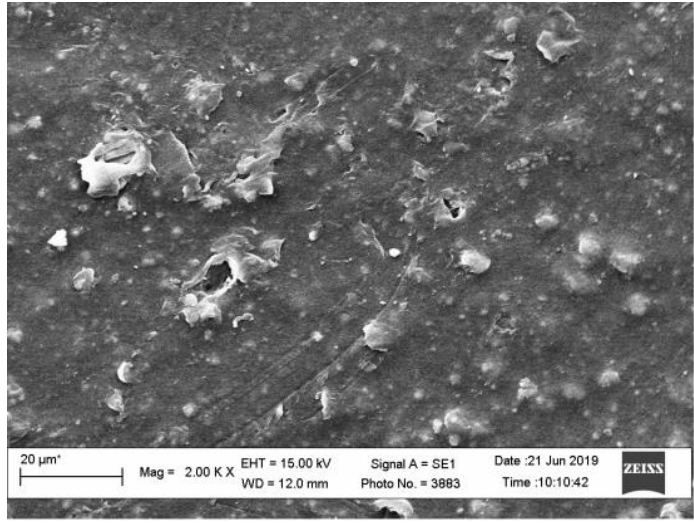

b

Fig. 10. Defectes on surface of polyethelene film modified with Vatpol filler (up to 21 wt.\%): a - X 1000; b - X 2000

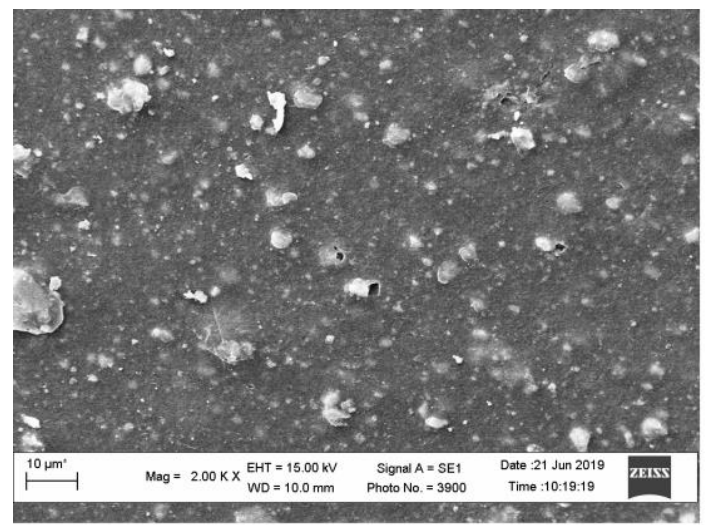

a

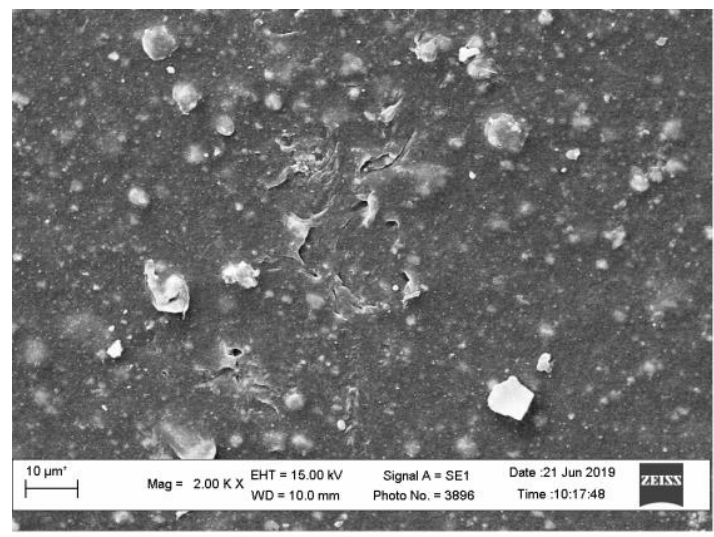

b

Fig. 11. Changing the surface structure of the polyethelene film modified with Vatpol filler (22.6 wt.\%) after 7 years of closed storage: $a, b-X 2000$.

total defect of the matrix. However, the defects which formed as pores $\left(\varnothing_{\text {por. }}=1.2 \cdot 10^{-6} \mathrm{~m}\right)$ and cracks $\left(\ell_{\text {crack. }} \leq\right.$ $4.5-6.5 \cdot 10^{-6} \mathrm{~m}$ at width of $b_{\text {crack. }} \leq \approx 0.9 \cdot 10^{-6} \mathrm{~m}$ ) formed a near large fragments of fillers with the size of $\ell_{\text {fil. }}=$ $9.5 \cdot 10^{-6} \mathrm{~m}$. The intra-crystalline formation of the polymer matrix was inhibited.

Increase the quantity of mixed filler to $23 \mathrm{wt} . \%$ did not change the total view of the surface of the modified polymer film (the filler of the two types had similar largest particle sizes $-\ell_{\text {fil. }}=4.4-9.5 \cdot 10^{-6} \mathrm{~m}$ ), although the quantity of large inclusions based on the filler in the surface of the film increased, and, respectively, the quantity and size of defects at the interface between the main and additional materials increased slightly (Fig. 11, a, b, Fig. 12). The apparent porosity was estimated for films with Vatpol filler in the support $\varnothing_{\text {por. }}=0.6$ $1.4 \cdot 10^{-6} \mathrm{~m}$, and for analogs with Credolen filler $-\varnothing_{\text {por. }}=$ $2 \cdot 10^{-6} \mathrm{~m}$. However, the length of the cracks $\left(\ell_{\text {crack }} \approx\right.$ $2.6 \cdot 10^{-5} \mathrm{~m}$ ) and their width significantly increased.

Increasing the quantity of organic-mineral filler to 
28 wt.\% can significantly affect the course of the aging process and, accordingly, cause changes in the surface structure of the samples. Such polymer films were characterized by an increased number of exits of the filler to the surface (Fig. 13). However, active coagulation of the filler particles was observed. The sizes of the formed formations reached $\left(\ell \approx 4.5-6.5 \cdot 10^{-6} \mathrm{~m}\right)$. The resulting defect was estimated by the pore size $\varnothing_{\text {por }} \approx 5 \cdot 10^{-6} \mathrm{~m}$.

However, the most characteristic indicator of the increased influence of the filler was the emergence of

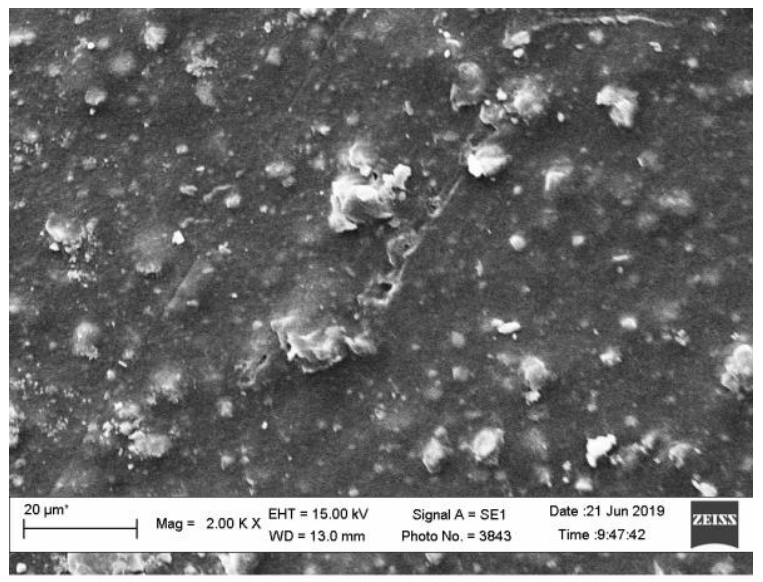

Fig. 12. Increase in defects in surface of polyethelene film with Credolen filler (23.2 wt.\%) for 7 years of storage. X 2000.
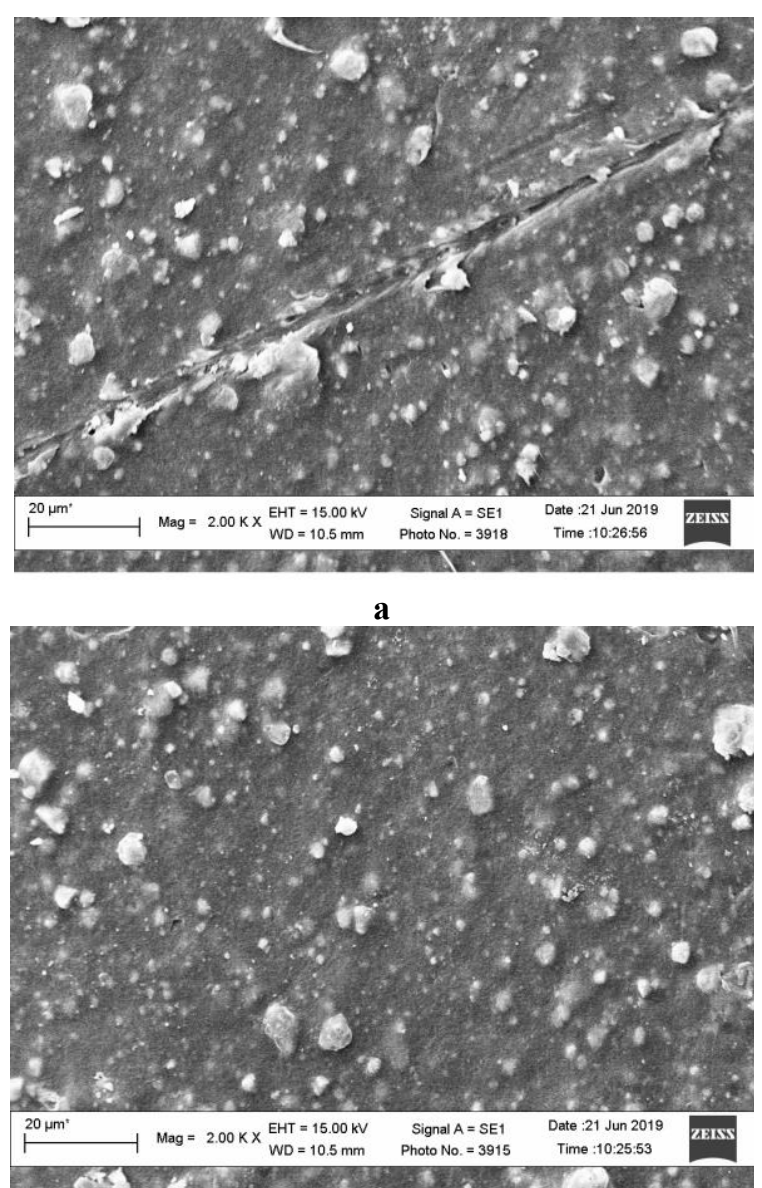

b

Fig. 13. The surface structure of polyethylene film with increased content of Vatpol filler (up to 28 wt.\%) after 7 years of closed storage: a, b - X 2000 . large "trunk" cracks $\left(\ell_{\text {crack. }} \approx 4.7 \cdot 10^{-5} \mathrm{~m}\right)$, which were formed in the directions of the film extrusion (when manufacture) and along the lines of places with increased concentration of the filler. No lateral branches in the form of small cracks were observed in such defects, in contrast to similar damage formed during mechanical loading of some types of polymers [1].

\section{III.Discussion}

Aging of composite materials during 7 years significantly increased the course of the destructive processes, which was revealed in the deepening of the caverns, widening of pores and cracks (Fig. 8-13). The nature of the influence of the type of filler on the passage of the aging process was singled out. For polyethylene films with organic filler (casein), the temporal changes of the structure were determined by the increase in the crystallinity of the matrix, which by the 7 th year of storage was exhibited in the formation of a certain quantity of crystallites of polyethylene, which grew out of the amorphous matrix (Fig. 8). Such growth of polyethylene crystals is more characteristic with the aging of matrices enriched with crystallization accelerators, in the form of gas corrosion inhibitors of metals which injected for a specific purpose into the polymer [2]. In inhibited polymer coatings, such processes, as a rule, proceed early as 3-4 years, achieving a significant development of crystallization processes, which turn into degradation at $5-6$ years [3]. Such development of structure formation processes is quite unexpected, since the formation of the structure in samples with organic filler is more consistent to films with plasticizer additives, which due to the increased amorphousness results have less surface defect [4].

The passage of crystallization is unifying factor in the aging process of two polyethylene films with additives wich have different effects on the polymer matrix. In both cases, the formation of crystalline polyethylene in the film can be attributed to a special type of germination of single crystals, which is significantly different from grown from solution [5]. Increasing the size of crystals in thin polyethylene film takes place at temperatures below crystallization and, unlike the increase in crystallite size (crystal thickening) in solution or melt, is carried out in the directions both perpendicular and along the surface of the film. This means that the change in the crystal volume is not due to the lateral reduction of the crystal itself, but is due to the transformation of the amorphous material. However, such processes can occur under the condition that the total mass of the matrix amorphous material is limited and/or the space-geometric boundaries that occur in thinfilm structures. It should be remembered that such transformations can be carried out with the observance of certain thermodynamic postulates, one of which provides for the possibility of increasing the crystal size, provided that the crystallization temperatures of two neighboring areas with different molecular masses are reduced by a certain mechanism without any rearrangement of the crystal lamellae [5].

The initial growth of the polyethylene crystals in the 

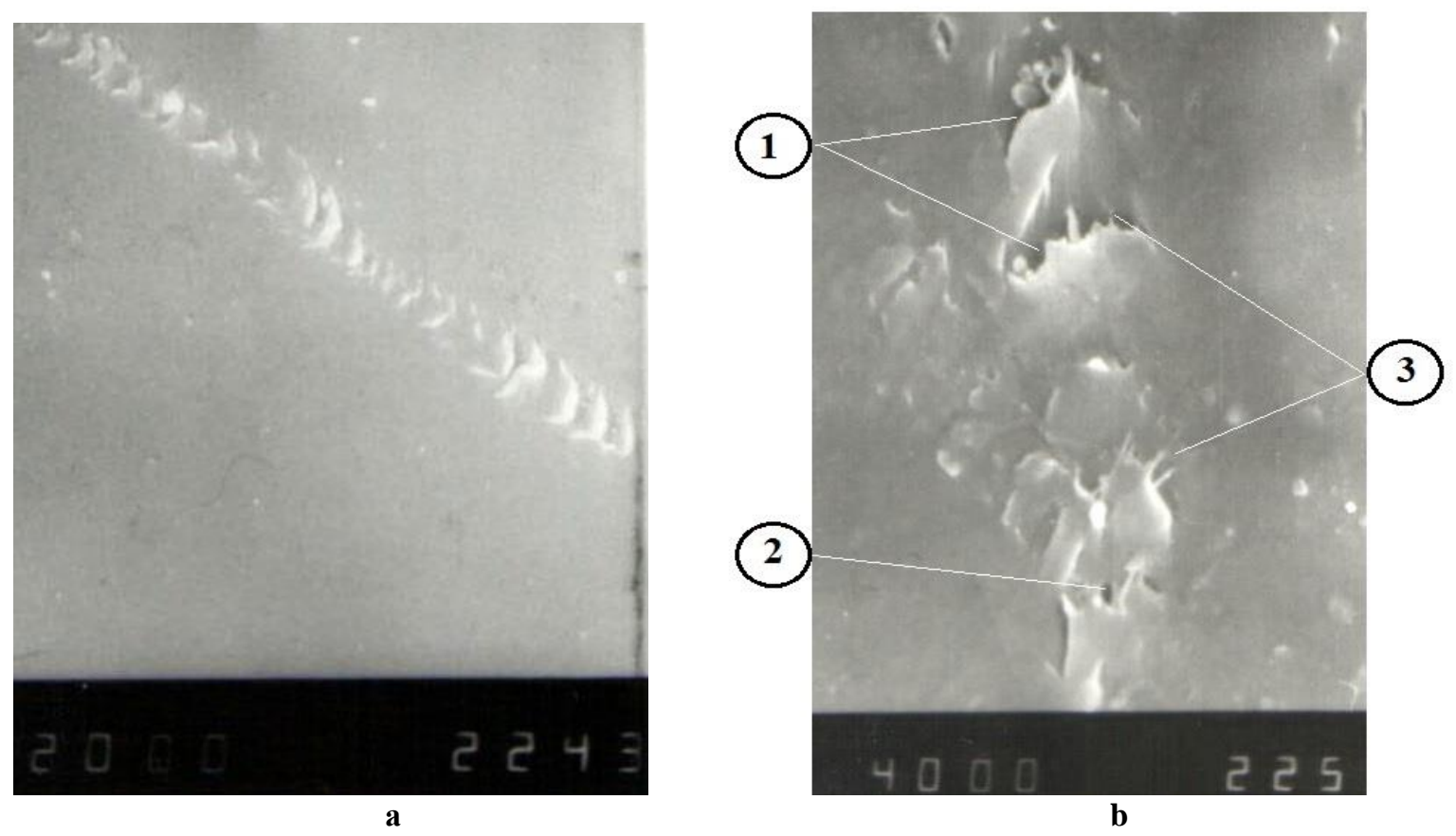

Fig. 14. Laying of polyethylene crystallites in films with amine gas corrosion inhibitors during aging: a - at 5.5 years (X 2000); b - 7 years (X 4000); 1 - the origin of cracks, 2 - pores, 3 - growth of needle-like crystals. The micrographs were obtained on electron microscope Tesla-250.

extruded film could start immediately after the manufacturing process - this is the initial outline of the crystal growth direction in the form of an angle (Fig. 2a). Such growth is characteristic for the formation of crystals at low temperatures from different solutions $\left(\mathrm{T} \leq 90{ }^{\circ} \mathrm{C}\right)$ $[5,6]$ and, in our opinion, occurs in the manufacture of thin films with the help of an extruder (the temperature of the extruder head is $\mathrm{T} \approx 140^{\circ} \mathrm{C}$ [7]) and their rapid.

The formation of the crystal proceeds with a certain inclination to the surface of the polymer film and the "hiding" of most of the single crystal in the amorphous matrix. Since further crystallization of other crystals occurs in the immediate vicinity of the first formed single crystal, and the formation of the crystal is energetically more favorable due to the amorphous matrix material than due to the adjacent crystalline structure, the longterm aging and crystallization result will be in the form of sequentially layered crystallites (Fig. 8, Fig. 14). These studies are in agreement with the idea that the initial deformation and orientation of the molecules affect the free energy of the polymer matrix, change the degree of hypothermia, which, as a consequence, affects the kinetics of cluster formation and the orientation distribution of the obtained crystals [8].

Moreover, each subsequent crystal will suppress the growth of the previous one, which will be deprived of the opportunity to make full use of the amorphous nature of the matrix material. Because of this, the formed crystalline structures will not be large, furthermore - they will be deprived of the ability to create large aggregates in the form of crystalline layers and, in the following, of spherulites [6]. However, such structure formation is more characteristic of polyethylene film materials, where the quantity of matrix amorphous material is limited, and one of the conditions for forming the structure is the cooling rate of the sample. In [9] the influence of the rate of supercooling of the solution on the rate of formation of crystalline embryos in a polymer matrix is considered. There are three characteristic thermodynamic regimes under which certain types of nucleation can occur, as well as possible directions of growth and size of crystallites. Among other things, it was concluded that the cooling rate (which corresponds to mode II, that, is not extremely fast, which is typical for obtaining a polymer film on the extruder) contributes to the formation of a certain number of clusters from which crystals of middle (for polyethylene) size grow.

Of course, the conditions for obtaining crystalline formations from homopolymer materials from solution are more predictable, but their forms and general appearance are more varied. The growth and size of the crystals that are observed depends on the molecular weight of the polymer and the crystallization conditions, such as the temperature and nature of the solvent [6]. When homopolymers crystallize from very dilute solutions, they can not only form lamellar crystals, but also create entire aggregates of dendritic form, the growth of which can be regarded as the creation of twodimensional embryos that cause the formation of steps with a certain slope to the surface $[10,11]$.

The development of a combined amorphouscrystalline structure in a thin film inevitably gives rise to two types of defect:

a) at the boundary of amorphous and crystalline phases;

b) in the direction of germination of single crystals, since the angle of inclination to the surface of the film for each subsequent crystal may increase slightly, and the 


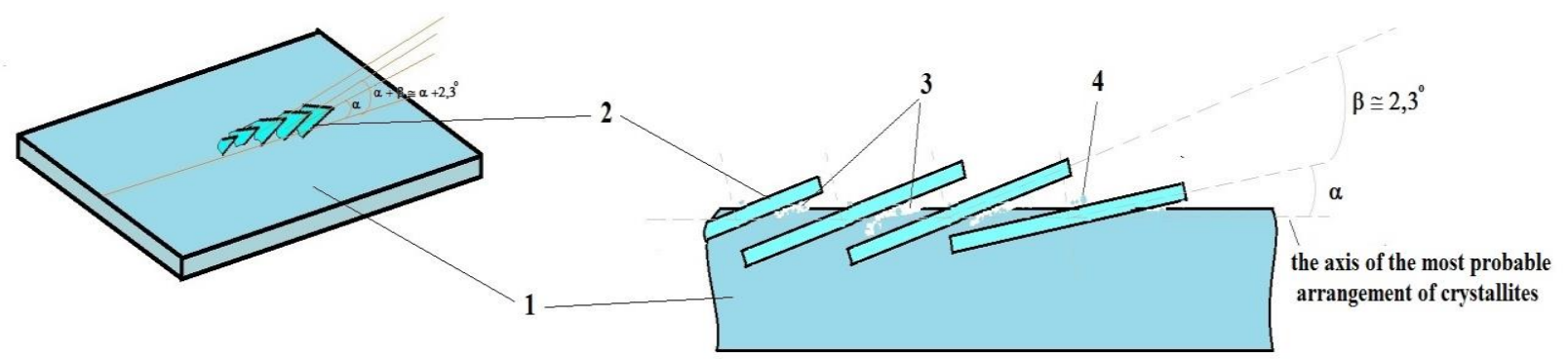

a

Fig. 15. Scheme of formation of crystals of polyethylene from amorphous film during aging: 1 - polyethylene matrix; 2 - crystals of polyethylene; 3 - places of using amorphous material for the development of crystalline structure, the formation of caverns and cracks; 4 - accumulation of amorphous material at the exit points of crystals: a - general view; b - side view.

depth of the cavern between the crystals will deepen (Fig. 15), and therefore the quantity of amorphous material serving as a corresponding "plug" in cavern decreases. Some aspects of crystallization in thin polymer films, in particular the orientation relative to the substrate or the film surface and the effect of the crystallization process temperature on the formation, are highlighted in $[12,13]$.

Of course, there are changes in structure, deviations in crystallinity growth, or defects increase in polyethylene grown from mortar or melt, during longterm aging. In addition, the overall growth of individual crystalline groups may occur with larger layers or at all one in other as dendrites or in other forms (Fig. 16) [6, 14]. However, such structural transformations are marked by the ability to obtain polyethylene crystals of the correct form, and may vary in shape depending on the conditions of obtaining (not necessarily orthorhombic).

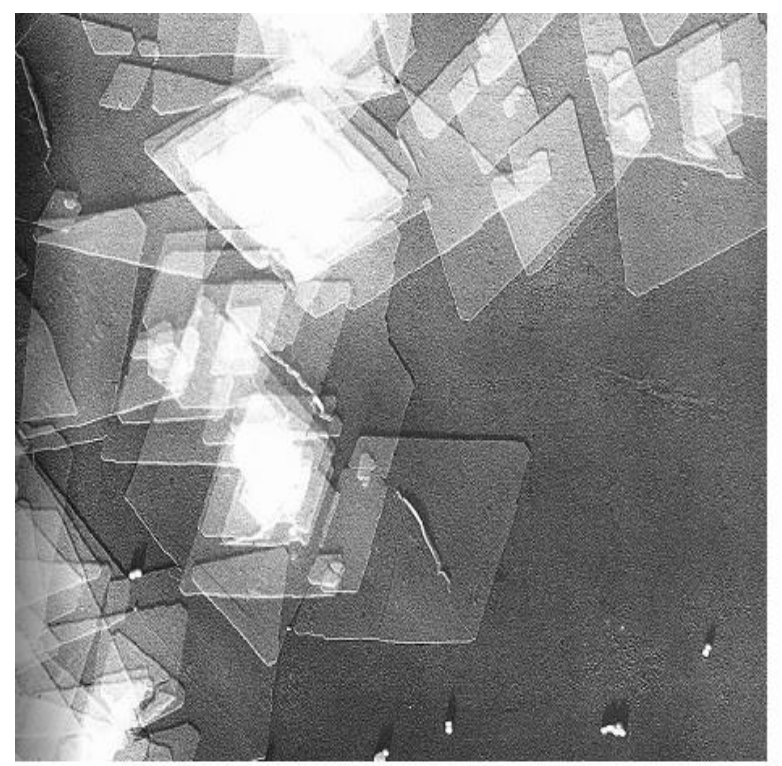

Fig. 16. Micrograph of linear polyethylene grown from tetralin solution at $89{ }^{\circ} \mathrm{C}$. Image courtesy of Dr. R. V. Rice [6].

The consequence of the elongated transformation of the polyethylene structure during aging is the formation of a large number of defects, which transition from surface to volumetric. Additives to polyethylene in the form of fillers contribute to the increasing in structural imperfections. However, the organic casein filler does not lead to changes with rapid degradation of the material. Such specimens were characterized by a small porosity (which increased from $\varnothing_{\text {por. }}=1.2-1.5 \cdot 10^{-6} \mathrm{~m}$ in the initial film to $\varnothing_{\text {por. }}=1.2-1.5 \cdot 10^{-6} \mathrm{~m}$ in the aging sample) and breaks in the form of cracks $\left(\ell_{\text {crack. }} \approx 1\right.$ $1.2 \cdot 10^{-5} \mathrm{~m}$ in the absence of such in the initial sample). Although the course of aging in films with organic filler combines the different directions of the destruction processes inherent in polyethylene films with the additives of diverse effects on the matrix.

Additives of mixed fillers significantly affected the morphological features of the surface. In the initial modified samples, the pore size was not large $\left(\varnothing_{\text {por. }} \approx\right.$ $0.4-0.6 \cdot 10^{-6} \mathrm{~m}$ ), but with aging their size increased (to ( $\varnothing_{\text {por. }} \approx 1.4-3 \cdot 10^{-6} \mathrm{~m}$ ). However, the most noticeable effect on the formation of cracks was found by the inorganic filler. The size cracks in the initial modified samples with a significant content of filler reached $\ell_{\mathrm{cr} .} \approx$ $4-6 \cdot 10^{-6} \mathrm{~m}$, and in aging during 7 years $-\ell_{\mathrm{cr} .} \approx 4.7 \cdot 10^{-5}$ $\mathrm{m}$. Thus, with further aging, the size of such cracks would also increase, judging by the development of this defect. Of course, such defectes were caused by several factors, one of which is the additional quantity of crystalline material in the form of filler, its phase and structural incompatibility with the matrix material, which would have to be offset by the addition of other substances.

The prolonged aging of the polyethelene films with the filler reflected another feature in the crystalline material growth - its possible recrystallization (the uncertainty of the statement is related to the quantity and type of technological active additives that are added to the raw pellets during manufacture). Such a process in polymer modified films can be reflected in the form of changes in the surface morphology of a matrix material with a well-formed crystalline structure with complete passivity of the mineral filler. It was possible to notice special formations, which were concentrated in places of 


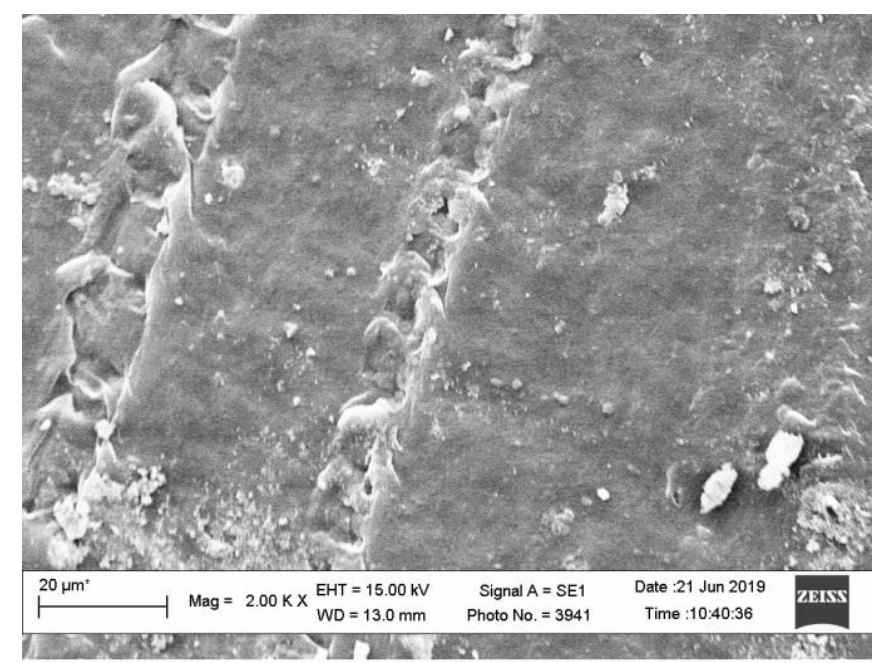

a

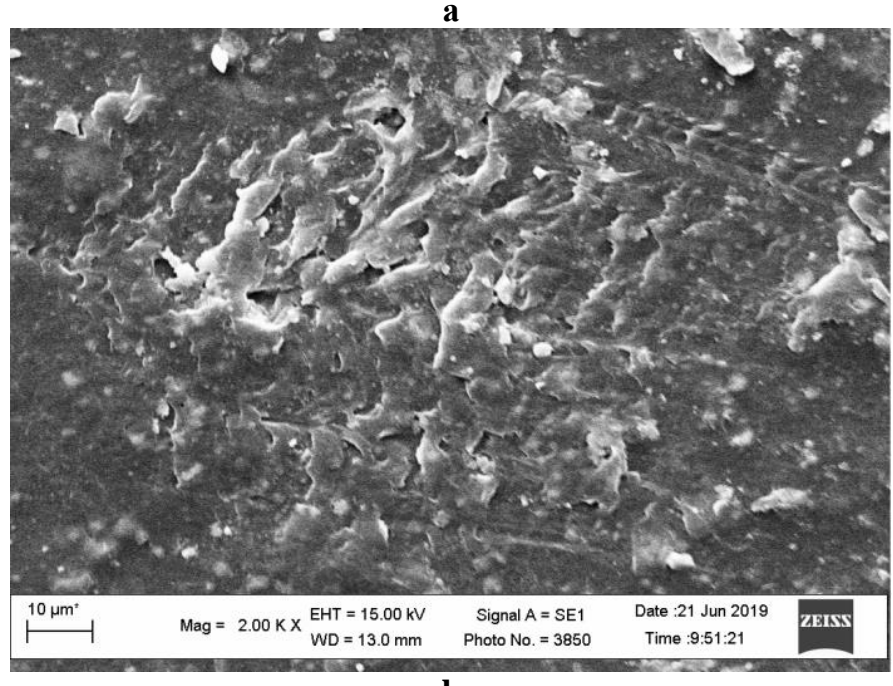

b

Fig. 17. Appearance of structural imperfections (7 years of storage) at recrystallization of thin poyethelene films modified with fillers (X 2000): a) $16.1 \%$ wt casein; b) 23.2 wt. \% Credolen.

intensive formation of crystalline structure in some sections of films with additives, as early as 6-7 years of storage. For films with organic filler casein is the socalled "track" in the form of crystallites of polyethylene, and for films with organic-mineral filler - places of exit to the surface of the inorganic filler (Fig. 17). As in the case of the "free growth of crystalline-amorphous arrays" from solution, the formation of similar aggregates in thin films, their organization and formation from polymer molecules is a problematic question, since the constituent influences in the form of stresses, that arise during the formation, and the rate of cluster formation depending on the cooling rate upon manufacturing. The last question was widely reflected in $[9,10,15]$. In addition, additives to the polymer matrix in the form of filler greatly change the kinetics of crystallization of the matrix.

The two types of agglomerate formations shown during recrystallization of polyethylene modified films do not exclude other types of formations that may occur during the aging of films obtained in other technological modes, with different composition, additives or with increased aging time. Thus, the processes of recrystallization during aging in the inhibited polymer films were exhibited in the form of growth of needles that grew out of the crystalline polymer material (Fig. $14 \mathrm{~b})$. Such an aging process is more characteristic of thin-film metallic surfaces, where such formations are especially harmful in passive elements of the chips (which can lead to breakage chips). Transition of chip technology to an organic basis, creation of new types of LEDs, transistors, radio frequency identification technology (commonly known as RFID), spintronics devices and other devices are limited by problems of their manufacture, but also by organization of stable long-term work, in which aging processes are key for long-term operation [9, 16-18].

\section{Conclusion}

Injection additives and fillers into the polyethelene material during manufacture uniquely lead to a change in the structure and physical- chemical characteristics of the polymer matrix. The development of structural transformations that take place during the aging of such films, both in the process of exploitation and/or during storage, also changes. Therefore, the long-term use of such polymer films requires consideration of both the 
initial formation of the thermoplastic and the possible directions for the development of structural transformations (degradation processes), taking into account the diverse action of the components that make up this composite.
Domantsevich N.I. - Professor, Doctor of Science (Engineering), Professor, Department of Commodity Studies and Expertise in Customs;

Yatsyshyn B.P. - Professor, Doctor of Science (Engineering), Professor of the Department of Electronic Devices.

[1] J.A. Brydson, Plastics materials (Butterworth-Heinemann Linacre House, Oxford, 1999), (ISBN - 07506 41320 ).

[2] N. Domantsevych, O. Aksimentyeva, B. Yatsyshyn, Current trends in commodity science. Packaging : Zeszyty naukowe (Poznan) 186, 67 (2012).

[3] N. I. Domantsevych, B.P. Yatsyshyn, M.N. Kril', Phys. Chem. Solid St. 19(1), 95 (2018) (https://doi.org/15330/pcss 19.1.95-99).

[4] N.I. Domantsevych, B.P. Yatsyshyn, Phys. Chem. Solid St. 4(2), 323 (2003) (ISSN 1729-4428 (Print); ISSN2309-8589 (Online).

[5] U.W. Gedde, A. Mattozzi, Adv Polym Sci, 169, 29 (2004) (https://doi.org/10.1007/b94176).

[6] L. Mandelkern, Crystallization of polymers (Cambridge University Press, New York, 2002).

[7] O.V. Saburlyak, P.I. Bashtannyk, Technology of processing of polymeric and composite materials (Kyiv, 2006).

[8] L. Jarecki, Progress in Understanding of Polymer Crystallization (Eds. G. Reiter \& G. R. Strobl). (Springer, Berlin Heidelberg, 2007), 64. (https://doi.org/10.1007/b11903420).

[9] M. Geoghegan, G. Hadziioannou. Polymer electronics (CPI Group Ltd, Croydon, 2013).

[10] L. Mandelkern, Crystallization of Polymers: Volume 2 (Kinetics and Mechanisms) (Cambridge University Press, New York, 2004) (www.cambridge.org/9780521816823).

[11] I.V. Mochalov, The growth of optical crystals (NRU ITMO, St. Petersburg, 2012).

[12] G. Reiter, I. Botiz, L. Graveleau, N. Grozev et al., Progress in understanding of polymer crystallization (Eds. G. Reiter \& G. R. Strobl), (Springer, Berlin Heidelberg, 2007), (https://doi.org/10.1007/b11903420).

[13] T. Yamamoto, Adv Polym Sci. 191, 36 (2005).

[14] J.W. Mullin, Crystallization (Butterworth-Heinemann Linacre House, Oxford, 2001) (ISBN- 0750648333 ).

[15] K. Kaji, K. Nishida, T. Kanaya, G. Matsuba, T. Konishi, M. Imai, Adv Polym Sci. 191, 190, 2005.

[16] G.V. Baryshnikov, D.Yu. Volyniuk, I.I. Gelzhinsky, Z.Yu. Gotra et al, Organic electronics (Lviv Polytechnic Publishing House, Lviv, 2014) (ISBN 978-617-607-673-5).

[17] M. Geoghegan, G. Hadziioannou, Polymer electronics (CPI Group Ltd, Croydon, 2013) (ISBN 978-0-19953382-4 (hbk.) 978-0-19-953383-1 (pbk.).

[18] B.D. Malhotra, Handbook of polymers in electronics (Rapra Technology Limited, Shrewsbury, 2002) (ISBN: 1-85957-286-3).

\title{
Н.І. Доманцевич ${ }^{1}$, Б.П. Яцишин ${ }^{2}$
}

\section{Зміна структури поліетиленових плівок під час довготривалого старіння}

\author{
${ }^{1}$ Львівський торговельно-економічний університет, Львів, Україна, nina.domantzevich@gmail.com \\ ${ }^{2}$ Начіональний університет “Львівська політехніка”, Львів, Украӥна, bogdan.yatsyshyn7@gmail.com
}

\footnotetext{
Проведено структурні дослідження поверхні композитних поліетиленових плівок при їх виготовленні та після 7 років закритого складування. Електронно-мікроскопічними дослідженнями встановлено особливості структуроутворення та проходження процесів старіння у залежності від кількості органічного та органічно-мінерального наповнювача, а також характерні особливості деструкції матричного полімерного матеріалу.

Ключові слова: полімери, поліетиленові плівки, наповнювач, структура, старіння, закрите складування.
} 